\title{
Toxic Anterior Segment Syndrome (TASS) and Prophylaxis Against Postoperative Endophthalmitis
}

\author{
Rosario Díez, Lourdes Jordano and César Hita \\ Hospital Universitario de Getafe \\ Spain
}

\section{Introduction}

Cataract surgery with intraocular lens (IOL) implantation is the most frequently performed operation in people over 65 years old. It has high success rates and complications are rare, but they do occur and can be either infectious or non infectious. Since the 1980s cases have been reported, usually as series of cases, of important inflammation in the anterior segment of the eye sometimes even with hypopyon and tissue damage after cataract surgery due to the entrance into the eye of toxic substances. They were first referred to as sterile endophthalmitis even if only the anterior segment was involved. In 1992, Monson et al (Monson et al., 1992) termed it Toxic Anterior Segment Syndrome (TASS).

\section{Incidence}

TASS can present as sporadic cases or in outbreaks. Many eyes with TASS are never diagnosed and many are not reported because they are not severe or they represent a very low percentage of the total cataract surgeries performed, thus the real incidence rates for TASS are unknown. But when a few cases accumulate in a short period of time, specially if they are severe, surgical centres search for information so as to prevent future cases.

\section{Clinical spectrum}

TASS is an acute and sterile anterior segment inflammatory reaction which usually presents after anterior segment surgery. Its incidence is unknown and it is due to the entrance of toxic but non infectious substances into the eye. It typically starts within 12 to 48 hours of intraocular surgery, but it can also occur even later. Symptoms include blurry vision and minimal to moderate ocular pain. Signs such as inflammatory cells or flare or even fibrin in aqueous humour, and diffuse (limbus to limbus) corneal oedema without vitreous involvement are characteristic (Figure 1). Most of the cases are reported after uneventful cataract surgery. Recently, TASS after phakic IOL surgery or vitrectomy has also been reported. Although many symptoms and signs are similar to those of endophthalmitis, TASS characteristically affects the anterior segment and is Gram stain and culture negative and improves with steroid treatment. 


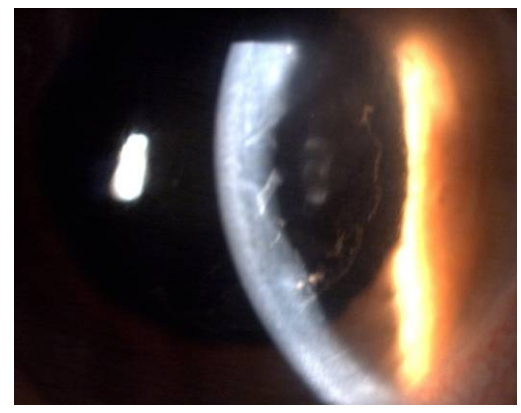

Fig. 1. Cornea oedema and fibrin on the IOL

Inflammation can be very severe resulting in hypopyon and fibrin formation due to the leakage of the blood-aqueous barrier. Limbus-to-limbus corneal oedema is a very typical sign resulting from diffuse endothelial damage. In some cases, severe tissue damage can lead to corneal decompensation requiring Descemet's Stripping Automated Endothelial Keratoplasty or Penetrating Keratoplasty. Epithelial downgrowth over Descemet's membrane has also been reported as a complication of TASS by Wallace, which required surgical treatment (Wallace et al., 2007). In early stages of TASS patients can present with low intraocular pressure. Permanent damage to the trabecular meshwork may cause ocular hypertension or secondary glaucoma which may require filtering procedures or tube shunt devices. Iris damage may cause a fixed irregular and/or dilated pupil.

\section{Differential diagnosis}

The differential diagnosis of (infectious) endophthalmitis can be challenging but there are some clues which can be helpful to diagnose TASS. TASS starts in the early postoperative period, usually within the first 24 hours. Inflammation is limited to the anterior structures of the eye and responds to either topical or oral steroids which can be given as a trial under strict monitoring as a steroid can improve TASS but unfortunately can theoretically exacerbate endophthalmitis if given too early in the course of treatment of the latter. There is a diffuse limbus to limbus oedema in TASS, pain is minimal or absent, and usually there is no lid swelling, conjunctival chemosis or discharge.

Unfortunately, none of the above mentioned symptoms and signs totally rule out the possibility of postoperative endophthalmitis. Gram stain and cultures from aqueous and vitreous taps are always negative in TASS but this could also happen in endophthalmitis when either the sample is too scarce or the bacterial count is too low. Pijla et al and the Endophthalmitis Vitrectomy Study reported that only 65 to $70 \%$ of all infectious endophthalmitis cultures were positive (Pijla et al., 2010) (Endophthalmitis Vitrectomy Study Group, 1995). Therefore, it should be remembered that the primary objective if suspecting TASS in a patient is to rule out postoperative infectious endophthalmitis, because postponing its diagnosis and treatment could be blinding for the eye's functionality and cause severe permanent damage to the anatomy of the eye.

\section{Aetiology}

As mentioned above, the aetiology of TASS is not infectious. It has been associated with many entities that reach the interior of the eye at any time during the surgery in the 
operating theatre. They can be divided into extraocular substances which penetrate in the anterior chamber during or after surgery (topical antiseptics, glove powder or topical ointment), substances associated with the surgical procedure (anaesthetics, preservatives, inadequately reconstituted balanced solutions, ocular viscoelastic devices, mitomicin $\mathrm{C}$ or intraocular lenses) and irritants on the surface of intraocular surgical devices due to insufficient cleaning/flushing (detergents, gram-negative endotoxins in ultrasonic bath water, metal degradation in the surgical instruments or impurities in autoclave vapour). Many of the later are associated with reusable instruments.

TASS is usually reported as outbreaks which cause great concern in the surgical team. The broad spectrum of aetiologies mentioned above makes it very hard to know the real cause when TASS is present. Endothelial toxicity has been associated with many intraocular drugs and may be influenced by chemical composition, the concentration, the $\mathrm{pH}$, or the osmolality of the medication or vehicle or the addition of preservatives.

Breebart et al and Parikh et al studied the effect of intraocular irrigating solutions, instrument related contaminants and intraocular drugs on corneal endothelium (Breebaart et al., 1990) (Parikh \& Edelhauser, 2003) (Parikh et al., 2002). They concluded that the initial rupture of endothelial cell junctions and the acute lost of its barrier function was the cause of the corneal oedema seen with TASS. Whether the cornea returns to its preoperative status in absence of oedema depends on the remaining endothelial cells and their capacity to cover the damaged area where cells where lost.

The main factors involved in TASS are described in further detail as follows.

\subsection{Preservatives}

It is of capital importance that drugs injected in the anterior chamber are preservative-free. Benzalkonium chloride (BAK) was involved in several TASS cases (Liu et al., 2001) (Eleftheriadis et al., 2002). Topical benzalkonium chloride rarely affects the endothelium when used properly. Sodium metabisulphite has also been involved in TASS (Avisar \& Weinberger, 2010). It is used mixed with epinephrine when the latter is used in irrigating solutions to maintain good intraoperative pupil dilation (Data from Spain).

\subsection{Intracamerular anaesthetics}

Preservative free $0.5 \%$ bupivacaine and preservative free $2 \%$ lidocaine were reported to increase corneal thickness and opacification (Kadonoso et al, 1998). Conversely, the use of preservative-free $1 \%$ lidocaine has proved to be safe during phacoemulsification cataract surgery as it rapidly gets diluted to less significant concentrations in the anterior chamber so is washed off the cornea and iris to non-toxic level during phacoemulsification (Heuermann et al., 2002).

\subsection{Balanced saline solution (BSS) and endotoxines}

Kutty et al found that the existence of endotoxines in balanced saline solution (BSS) was responsible for an outbreak of TASS (Kutty et al., 2008). Further more, medications added to BSS can be another potential source of TASS.

\subsection{Maintenance of surgical materials}

Proper cleaning of surgical material is of cardinal importance in TASS prophylaxis as inadequate cleaning of phacoemulsification and irrigation/aspiration (I/A) handpieces is 
the most frequently identified practice associated with TASS. Residual ophthalmic viscoelastic devices (OVD), debris or chemical substances used in the cleaning protocol can deposit in the inner and outer surfaces of reusable instruments if they are not properly removed. This is more likely to happen with reusable surgical materials such as cannulas, phacoemulsification handpieces and I/A tips. Both Parikh and Jun concluded that both enzymatic and non-enzymatic detergents used in instrument cleaning can eventually be deposited in the lumen of these and damage endothelium of rabbit and human eyes (Parikh et al., 2002) (Jun \& Chung, 2010). Using detergents in wrong concentrations is another cause of TASS. Instruments processed with detergents should be rinsed with abundant sterile distilled or sterile deionized water. Needless to say, disposable material should never be reused. When instruments are sterilized they can also get contaminated. Ultrasonic baths dislodge dried debris from instruments, especially OVDs. Gram-negative bacteria can be found in water baths, ultrasound baths and autoclave reservoirs. This bacteria are destroyed during heat sterilization but their heat-stable bacterial wall endotoxines remain intact and can deposit on instruments (Kreisler et al., 1992) (Holland \& Morck, 2007) (Andonegui et al., 2009). Another author (Hellinger et al., 2006) found sulphate, copper, zinc or silica impurities in the autoclave steam moisture.

\subsection{Denatured ophthalmic viscoelastic devices}

OVD can remain adherenet to the lumen of cannulas and reusable I/A tips when these are not correctly flushed after surgery. During sterilization OVD are denatured becoming hazardous in the anterior segment (Mathys et al., 2008).

\subsection{Antibiotics}

Administration of intraocular antibiotics during surgery is a very common practice. Gills recommended vancomycin and gentamicin in the irrigating solution during cataract surgery for postoperative endophthalmitis prophylaxis (Gills, 1991). There is increasing concern about the development of vancomycin-resistant bacterial strains, especially because this antibiotic is used as a last-step drug for gram-positive bacteria. Even more, macular toxicity has been associated with gentamicin use in irrigating solutions and when injected intravitreally even though Ball did not find a macular thickness increase with the use of a combination of these two antibiotics in cataract surgery (Ball \& Barret, 2006). Furthermore, the concentration of these antibiotics used in irrigating solutions and the duration that they are in contact with bacteria responsible for endophthalmitis are not enough to be effective, based on their bactericidal or bacteriostatic characteristics (Peck et al., 2010). Other authors described the use of intracameral cefotaxime (Kramann et al., 2001), cefazolin (Garat et al., 2005) (Romero et al., 2006), and cefuroxime (Montan et al., 2002) (Díez et al., 2009), but no toxicity has been reported. Nevertheless, there is always a possibility that these antibiotics could result in TASS due to an error in drug concentration or $\mathrm{pH}$. This highlights the role of specially trained pharmacy staff.

\subsection{Autoclave}

Autoclaves must be periodically checked for preventive maintenance as recommended by manufacturer's direction. Even more, it is mandatory to check for this daily or, at least, weekly. Hellinger reported a case of TASS due to the quality of the water and vapour of a vapour generator autoclave (Hellinger et al., 2006). Sulphate, nickel, copper or zinc in 
vapour condensations can cause TASS outbreaks, which are specially severe with copper and zinc particles. When maintenance of the autoclave is poor this can result in an important source of debris. Thus, water composition used in autoclaves should be checked and substituted, if necessary, by deionized and ultrafiltered water. Glutaraldehide should not be used for sterilization as it is extremely toxic when insufficiently rinsed instruments contact cells of the anterior segment of the eye. Plasma gas sterilization promotes metal degradation in cannuled instruments and secondarily can cause TASS (Duffy et al., 2000).

\section{8}

Even though TASS is defined as an acute inflammation, it is not rare to find TASS delayed days after surgery. It is usually caused by intraocular lenses (chemicals used in packaging, polishing, cleaning or sterilization of the lens) or even ocular ointments (Figure 2). An outbreak was reported by Werner when ocular ointment containing petroleum was associated to tight ocular postoperative patching (Werner et al., 2006).

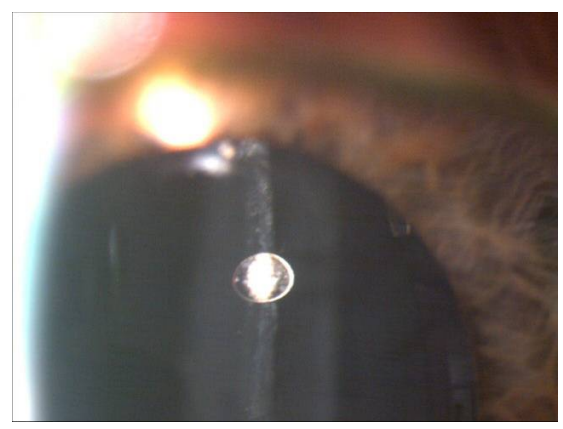

Fig. 2. Intraocular ointment drop in the anterior chamber

\subsection{Glove powder}

When powder enters the eye it can result in TASS. But some powder-free gloves release a compound that causes TASS even if gloves merely touch the IOL during surgery.

\subsection{Others drugs}

Five cases of severe intraocular inflammation that developed after an intravitreal injection of the same lot of bevacizumab have recently been reported. Taking all observations together, the authors suggest that the cause of the sterile endophthalmitis associated with lot B3003B01 of bevacizumab was the result of some toxic byproduct whose concentration may not be high enough when bevacizumab is given systemically. The degeneration during the storage may increase its toxicity, and the eyes sensitized by repeated intravitreal bevacizumab may respond to the increased antigenicity (Sato et al., 2010). Also, two cases of TASS have been reported resulting from impurities in generic trypan blue that was administered intracamerally to improve visualization of the capsule. The corneal oedema persisted and the patients developed endothelial and trabecular meshwork damage. Penetrating keratoplasty was performed in both cases (Buzard et al., 2010). 


\section{Management of TASS}

The treatment of TASS is centred on dampening the inflammation because once the toxic agent penetrates the anterior segment of the eye it causes immediate damage and unfortunately washing out the toxins is not effective in reducing the intense inflammatory reaction.

When an acute postoperative inflammatory reaction is present, the first thing to do is to rule out infectious endophthalmitis. Once this has been done hourly topical 1\% prednisolone acetate should be started. Close follow-up is mandatory in order to detect worsening inflammation or stabilization of the patient's condition. Of course, should the inflammation increase, even if cultures or gram stain results are negative, it is strongly recommended to initiate treatment for infectious endophthalmitis given the potentially catastrophic consequences of failing to treat the later condition quickly. Slit lamp evaluation is useful to document corneal oedema and fibrin or cells in the anterior chamber.

Intraocular pressure can initially decrease secondary to trabeculitis and in later stages can increase secondary to permanent trabecular meshwork damage. The eye should undergo gonioscopic exploration if corneal oedema allows it so as to inspect for the development of peripheral anterior synechias. Confocal microscopy, where available, allows determination of endothelial cell lost and study if permanent corneal damage is present. The final result will depend on the type of toxic, its concentration and the time it remains in the anterior chamber, and how long treatment was delayed. Mild cases of inflammation will recover corneal transparency in a few days or weeks, whilst moderate cases can exhibit a certain level of corneal oedema and/or ocular hypertension. The most severe cases will associate prolonged corneal oedema, corneal opacity, ocular hypertension or glaucoma, chronic anterior uveitis, cystoid macular oedema secondary to chronic inflammation and a fixed midriatic pupil secondary to iris damage. Ocular rehabilitation may include queratoplasty, trabeculectomy or tube shunt devices.

\section{What to do in TASS outbreaks? TASS prevention}

The most important thing to do is to create a team where all surgical staff are represented: surgeons, nurses, sterilization area staff, pharmacists, and ideally preventive medicine or public health doctors. The medical records from patients who developed TASS should be available for the team who should document the surgical procedure, clinical presentation, the first time the inflammatory process was diagnosed, therapeutic approach and follow up. Furthermore, data recording the names of everyone in the surgical team, anaesthetics, intraocular drugs or viscoelastic devices, intraocular lenses and surgical incidences should be registered and ready to be reviewed. It is important that lot or batch numbers of drugs, substances and intraocular lenses are documented. Practice protocols must be reviewed to detect any mistakes during their application. This is very important for those members of staff responsible for cleaning and sterilization (Mammalis et al., 2006).

The authors believe that reusable instruments should be replaced regularly, specially cannulas and I/A tips, even though lumen surface irregularities or deposits are not evident. Of extreme importance is to rinse with sterile deionized water both the irrigation and aspiration ports and the I/A tips of the phacoemulsifier. Because gram-negative bacteria growth is frequent in ultrasound water baths this water should be replaced daily.

To learn more about instrument cleaning, disinfection and sterilization measures we recommend the Recommended Practices for Cleaning and Sterilizing Intraocular Instruments (Hellinger et al, 2007). 
On the other hand, both irrigating solutions and any kind of intraocular medication should be correctly reconstituted. The authors believe that the operating room nurse in charge of intraocular drugs should repeat in a firm, loud voice the name of the substances he or she handles to the surgeon. It is also important to make sure that every intraocular medication is preservative-free and is of the proper concentration. This is specially important for epinephrine (adrenaline), which is frequently added to irrigating solutions, and intracamerular anaesthetics or antibiotics. It is important to note that lidocaine, indocyanine green, trypan blue and acetylcholine chloride are mixed with BSS instead of sterile water.

As most of the reported outbreaks of TASS are related to cleaning, disinfection and sterilization or reusable intraocular material, these should be the most thoroughly reviewed steps (Holland et al., 2007). Therefore, when an outbreak of TASS is detected the maintenance of autoclave should be emphasised as well as improving cleaning, disinfection and sterilization practices. Of great importance is following the directions for management of equipment provided by the manufacturers.

It is mandatory to report TASS cases to Regional or National Public Health Departments depending on each country's organization.

\section{Conclusions}

Toxic Anterior Segment Syndrome is a challenging postsurgical inflammatory process both as isolated case or as outbreak. Today its clinical evolution is well-known. It is of capital importance to rule out infectious endophthalmitis because prompt diagnosis and treatment ensures better functional results. The low incidence or mild intraocular inflammation due to TASS or the fact that it is a sterile inflammation should not make clinicians underestimate this complication.

Unfortunately, it can be as destructive as infectious postoperative endophthalmitis. This fact highlights that either cleaning, disinfection or sterilization protocols should be improved or that some kind of intraocular medication has been used which is inadequate for this route. Thus, all the surgical team should be aware of this clinical entity, that any substance that is introduced into the eye is a possible cause of TASS and the different policies that can be incorporated to prevent it.

\section{Overview of Postoperative Endophthalmitis (POE) Prophylaxis}

Postoperative endophthalmitis (POE) is an uncommon but devastating intraocular surgical complication (Figure 3). As cataract surgery is by far the most frequently performed intraocular operation in the anterior segment, it is also the most frequent cause of POE and this has very important clinical, economic and legal consequences (Khan et al., 2005). Of note intraocular operations in which large amounts of the vitreous are removed are less likely to cause endophthalmitis as vitreous acts as a broth for the microorganisms involved. Although it is a rare complication POE is an important public health issue due to the progressive aging of the population and the millions of cataract surgery procedures done in a year all around the world. It is greatly feared as it can lead to severe and permanent visual loss. Over the years the phacoemulsification technique has improved with the use of smaller clear corneal incisions, faster surgical times, lens implantation, intraocular antibiotics, topical anaesthesia and sutureless wounds but endophthalmitis rates have not decreased as much as expected (Melo et al., 2010) (Barry et al., 2006) (Miller et al., 2005). 


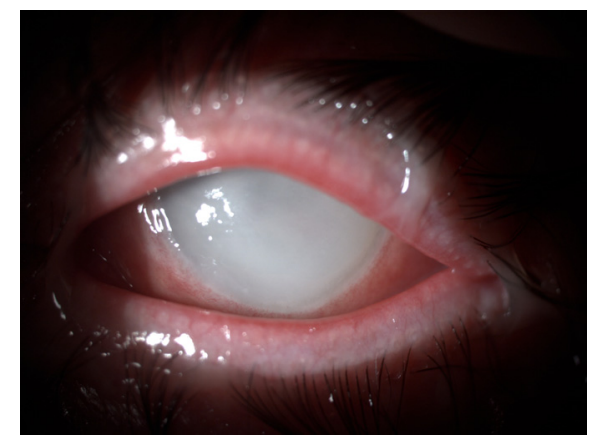

Fig. 3. Postoperative endophthalmitis with severe inflammation.

POE is an unexpected severe intraocular inflammation which affects both the anterior and posterior segments of the eye and is associated with vitreous echoes in both A and B modes with ocular ultrasound echography. A differential diagnosis of TASS and retained lens material is mandatory to consider. Diagnosis is based on the clinical features but cultures from aqueous and vitreous should be done. The most frequent cause is gram positive bacteria (Endophthalmitis Vitrectomy Study Group, 1995). Incidence has varied in the past decades- in the 1970's it was $0.32 \%$, in the 1980's $0.16 \%$ and in the 1990 's $0.08 \%$. In the first years of the $21^{\text {st }}$ century the incidence increased to $0.26 \%$. Different authors suggest that the cause may be non-sutured corneal incisions or postoperative hypotony. Incidence varies between series from $0.07 \%$ to $0.5 \%$ (Díez et al, 2009) (Miller et al., 2005).

The aims of prophylaxis in cataract surgery are to prevent postoperative endophthalmitis or surgical wound infection. Although the need for prophylactic antibiotics in clean surgical cases is debated among general surgeons, there is almost uniform agreement among ophthalmic surgeons on the need for antibiotic prophylaxis in the clean cataract surgical case because of the serious adverse effects associated with endophthalmitis. Some argue that antibiotics are not needed for clean surgical cases; however, because of the devastating effects of endophthalmitis, antibiotics are almost universally used for elective cataract surgery, even in healthy patients. Potential pathogens must be determined as well as local resistance patterns. An effective antibiotic must be selected, although no antibiotic is effective against all potential pathogens (Liesegang et al., 2001). It is not necessary to cover all potential pathogens or to sterilize the operative site, but it is necessary to eliminate most bacteria from the site. The least toxic and least expensive antibiotic should be selected; older antibiotics are not necessarily obsolete. The antibiotic must be administered at an appropriate time and dose. The antibiotic must be in the wound or anterior chamber at the time of introduction of organisms if the antibiotic is being used to clear an inoculation of introduced organisms. If the objective is to eliminate the bacteria from the surface, then topical antibiotics must be given time to work. It is not effective to administer the topical antibiotic only at the start of surgery, and it is minimally effective to administer the topical antibiotic after the wound is closed. The antibiotic should be administered for the shortest time possible and is usually not effective as a prophylactic in the postoperative period.

It is a general principle in infectious disease to avoid potent antibiotics for prophylaxis, as these should be reserved for therapy. If the patient gets a postoperative infection, generally a different antibiotic is selected for therapy. There are two approaches to prophylaxis. One is to reduce the number of organisms on the surface of the eye by using topically applied antisepsis 
and/or antibiotics. The other involves diffusion of antibiotics into the ocular tissues during the perisurgical period by topical, subconjunctival, systemic, or intracameral route.

\section{Effects on costs and quality of life}

Complications of endophthalmitis affect the patient's quality of life. These include: loss of vision, corneal opacity $(21,3 \%)$, secondary cataract $(40,4 \%)$, intraocular pressure increase $(29,8 \%)$, residual vitreous opacity $(63.8 \%)$, macular epirretinal membrane, retinal detachment $(6.4 \%)$ or even enucleation (Miller et al., 2005). The patient will likely undergo intraocular injections, some times vitrectomy, and requires close follow-up. Secondarily, the patient may need other operations for the complications mentioned above. All of these involve an important decrease in the patient's quality of life and a significant economic cost.

\section{Risk factors}

\subsection{Local risk factors}

Any infectious or even inflammatory local process may be considered as a risk factor for POE. Some authors found that chronic use of topical medication, contact lens wear, blepharitis, chronic dacriocystitis, and chronic eyelid or conjunctival inflammation were associated to higher conjunctival contamination rates and multiresistant bacteria (Miño de Kaspar et al., 2003, 2009). Therefore these conditions should be treated prior to elective cataract surgery. It is known that external ocular microorganisms are responsible for intraocular infection after surgery (Speaker et al., 1991) and presurgical protocols for treating bacterial endophthalmitis are not effective to guarantee sterility (Ciulla et al., 2002). When preoperative topical drugs for unusual conjunctival bacteria such as coagulasenegative Staphylocci or Corynebacteria species were used, the organisms grew back 48 hours after the treatment was interrupted (Fernández Rubio et al., 2004). It was suggested that these bacteria had some kind of reservoir from where they colonized the conjunctiva. Thus, if more aggressive bacteria remain in the conjunctiva for a long period of time this would increase the risk for intraocular contamination after cataract surgery.

There is a strong association between atopic dermatitis and Staphylococcus (S.) aureus conjuntival colonization increasing the risk of intraocular infection due to this organisms (Nakata et al., 2000). In patients with chronic blefaritis S. aureus, S. epidermidis, P. acnes and corinebacteria were found more frequently (Groden et al., 1991). Gram-positive cocci, S. aureus and Streptococcus pneumonaie are associated with acute forms of dacriocystitis whilst gram-negative bacteria like Haemophilus influenzae, Pseudomonas species and enterobacteria are more frequent in the chronic form (Mills et al., 2007).

\subsection{Senior versus training surgeons}

There is not enough evidence to presume that senior surgeons have lower incidence rates of endophthalmitis than residents or fellows (Hollander et al., 2006) (Kamalarajah et al., 2007). Training surgeons may have more posterior capsule ruptures whilst senior surgeon may not suture as many corneal incisions arising from cataract surgery as the former.

\subsection{Intraocular lens (IOL)}

The role of intraocular lenses in endophthalmitis has not been fully established. Infections have been reported with both injectable and non-injectable IOLs. The trend is to use 
injectable lenses which allow smaller incisions and avoid contact and colonization with ocular surface bacteria, thus reducing the risk of an endophthalmitis. There is no difference between 1-piece and three-piece IOLs, but there are differences suggesting that silicone IOLs are more prone to intraocular infection due to surface factors (ESCRS Endophthalmitis Study Group, 2007). The most important factor may be the site of the clear corneal incision, in particular, when the incision is temporal (Schauersberger, et al.) (Baillif et al., 2009). Cusumano (Cusumano et al., 1994) and $\mathrm{Ng}$ (Ng et al., 1996) compared plymethilmethacrylic acid (PMMA) and hidrogel IOLs and found statistically significant differences in the adhesion of bacteria on the lens surface on non hidrogel lenses. Hidrogel IOLs are foldable, highly biocompatible and have a hydrophilic surface leading to a lower risk of endophthalmitis.

IOLs may also have their surface covered in heparine or fluor thus reducing bacteria adhesion and therefore inflammation and endophthalimtis (Arciola et al., 1994) (Eloy et al., 1993). Recently other authors have investigated drug delivery with intraocular lenses suggesting that antibiotic-soaked IOLs have potential to become a clinically significant technique in the prevention of postoperative endophthalmitis (Shaw et al., 2010).

\subsection{Surgical complications}

Intraoperative complications may increase the risk of POE. Posterior capsule tears with or without vitreous loss increases the risk of POE (Driebe et al., 1986) (Menikoff et al., 1991) (Kelkar et al., 2008) (Kim et al., 2007). The eye finds it easier to defend against bacteria when there is no vitreous in the anterior chamber, in fact, aqueous humour is contaminated in up to $20 \%$ of all patients at the end of cataract surgery, but only a very low percentage develops POE.

\section{Prophylaxis}

\subsection{Presurgical prophylaxis}

\subsubsection{Topic antibiotics}

Based on heterogeneous evidence, topical antibiotic agents are used worldwide as adjuvant of povidone-iodine for postoperative prophylaxis. The goals of prophylactic antibiotics in cataract surgery are to reach an optimal concentration in the aqueous humour and cornea and to reduce bacterial flora in the lids and conjunctiva sac. To do so, prophylactic treatment is started a few days before surgery or the day of surgery or using a combination of these strategies.

Gram-positive species are very common in conjunctival and lid flora. Vasavada et al (Vasavada et al., 2008) reported Staphylococcus species as the most prevalent of all being cultured in up to $90,4 \%$ to $94,4 \%$ of asymptomatic people. Of the Staphylococcus species isolated, 71\% were S. epidermidis. Gram-negative organisms included Pseudomonas aeruginosa, Pseudomonas stutzeri, Enterobacter cloacae, Enterobacter hormaechei, Proteus vulgari, and Acinetobacter species. The anaerobic cultures mainly consisted of Propionibacterium acnes and Peptostreptococcus species. Streptococcus species was present in $2 \%$ of all specimens.

The fourth-generation fluoroquinolones moxifloxacin and gatifloxacin achieve high anterior chamber concentrations and have a broad bactericidal spectrum. They have similar killing rates in vitro studies and appear to be more effective than earlier quinolones (Kowalsky et al, 2006). Thus, they are adequate to obtain an effective antibiotic concentration before the 
anterior chamber is penetrated to allow bacteria inside it. But it should be noted that the drug is rapidly washed out once phacoemulsification of the cataract begins.

\subsubsection{Systemic antibiotics}

Prior studies of intravenous antibiotics revealed poor intravitreous penetration. Antibiotics that reached significant levels may not reach minimum inhibitory concentration (MIC) for many hours. Vancomycin or aminoglycosides failed to reach MIC in phakic human eyes with intact vitreous cavities. Some authors consider that fourth generation fluoroquinolones should be considered as oral prophylaxis in high-risk patients such as those undergoing vitreous loss during cataract surgery, chronic blepharitis, lacrimal drainage obstruction or relative inmunocompromise although the authors do not.

\subsection{Surgical prophylaxis in the operating theatre \\ 12.2.1 Operating room}

POE outbreaks have been reported associated to operating theatre/room air conditioning systems, and they are usually caused by Aspergillus rather than bacteria. These outbreaks are often related to repairs in the operating theatre. Antiseptic solutions (povidone-iodine, clorhexidine), BSS, OVDs, mydriatic and antibiotic drops are also a source of contamination. Eye drops can be contaminated with Pseudomonas aeruginosa (Pinna et al., 2009) or Fusarium species (Cakir et al., 2009). Where possible, single dose eye drops should be used. If not available, a different bottle should be used in every different patient.

Correct cleaning and sterilization of the instruments is of critical importance and therefore, periodic monitoring of protocols and cleaning and sterilization systems are mandatory. The authors recommend following the manufacturers' practice guides focusing on cannulated instruments.

Antisepsia measures of the surgical team are also of chief importance, specially those related to hand scrubing.

\subsubsection{Povidone-iodine}

It is know that the most important sources of bacteria responsible for postoperative endophthalmitis are those in the conjunctiva and eyelids. One of the measures that have proven to be effective in postoperative prophylaxis is to decrease the amount of bacterial flora or occasional pathogens. Ciulla et al (Ciulla et al., 2002) describes several prophylactic methods concluding that $5 \%$ povidone-iodine irrigation before surgery was the most strongly recommended prophylactic measure.

It has proved to be effective against a wide range of bacteria, including methicillin-resistant Staphylococcus (MRSA) (Guzel et al., 2009), as well as fungi, protozoa and viruses. It has very rapid cytotoxic activity on prokaryotic cells once it reaches the cell wall (Lacey\& Catto, 1993).

Conjunctival irrigation with $5 \%$ povidone-iodine preoperatively is more effective eliminating bacteria from the ocular surface than the instillation of 2 drops (Miño de Kaspar et al., 2005). Irrigation has a mechanical effect as it washes bacteria away from the surface and crypts. A period of time ranging from one to three minutes should be waited for before washing povidone-iodine from the ocular surface. The skin of the eye lids and eye lashes should be cleaned with $10 \%$ povidone-iodine, but note that total sterilization cannot be achieved-approximately $20 \%$ of the resident flora are resistant to surgical scrubs and antiseptics. 
$5 \%$ povidone-iodine has been shown to be effective and safe. Its toxicity is limited to conjunctival irritation, keratitis and contact dermatitis. The entry of povidone-iodine in the anterior chamber should be avoided as it is toxic for the endothelium. Therefore, whenever used at the end of the surgery it should only be applied on the surface of the eye once the surgeon has made sure the incisions are sealed and the ocular pressure is not low.

$0.5 \%$ clorhexidine is safe and effective as an alternative skin disinfectant when the patient is allergic to povidone-iodine. It is also safe and effective in diminishing skin colonization with Staphylococci in patients before operation. It is not clear though if it is in practice as effective as povidone-iodine.

\subsubsection{Draping and topical anaesthesia}

Careful draping of the eyelid margins is of critical importance to reduce the incidence of anterior chamber contamination (Masket, 2007). Topical anaesthesia allows the patient to blink, which may increase the difficulty to properly retract the eyelids and carefully drape the lid margins. Hence, poor draping may be associated with the use of topical anaesthesia. There is no clear evidence to suggest topical anaesthesia as a risk factor for postoperative endophthalmitis. However, some retrospective studies concluded there was a higher incidence of endophthalmitis with topical anaesthesia compared to peribulbar or retrobubar anaesthesia (García-Arumi et al., 2007). On the other hand, Greenbaum (Greenbaum, 2007) considers the role of more frequent postoperative patching on eyes having retrobulbar anaesthesia as the factor which explains the lower incidence of endophthalmitis in these patients.

\subsubsection{Corneal incisions}

Two of the most important factors to consider under this topic are postoperative square corneal tunnel incisions and ocular hypotony. An entry wound that is distorted during surgery is more likely to permit the entrance of fluid from the ocular surface during and after the surgery. The width of the incision is also important as it is more dangerous to work through a $3.5 \mathrm{~mm}$ tunnel than a $2.5 \mathrm{~mm}$ tunnel. Another factor is wound localization, where temporal localization has been associated with a higher risk of endophthalmitis. Furthermore, a low intraocular pressure results in a poor apposition of the edges of the wound. The authors routinely hydrate the corneal stroma - this forces the apposition of the wound edges. Many critics believe this is a too temporary measure as they believe it lasts for 1 or 2 hours. Stromal swelling can persist 24 hours or more after the surgery (Fine et al., 2007). This can be proven with ultrasound.

Any incision suspected of incompetence should be considered for suturing as it increases the risk for potential infection. In the last few years tissue adhesives are gaining popularity. There are three possibilities: cyanoacrylate, polymerizing liquid hydrogel and fibrin glue. Their role in cataract surgery and in endophthalmitis prophylaxis has not been fully established.

\subsubsection{Antibiotics employed in the operating room}

In recent years there has been great controversy on the use of vancomycin as a prophylactic agent against endophthalmitis rather than a therapeutic agent. It is a bactericidal antibiotic. It is effective against gram-positive pathogens, including methicillin-resistant Staphylococcus species and Bacillus cereus. 
There is fear that its overuse as a prophylactic agent will permit the development of multidrug resistant bacteria. To prevent this from occurring, the Centers for Disease Control and Prevention (CDC) of the United States, in the year 1995, discouraged the use of vancomycin in irrigation solutions or as routine surgical prophylaxis (Centers for Disease Control, 1995). Despite these guidelines, many Ophthalmologists continue using it. Surgeons who use vancomycin in irrigating solutions justify its use based on the fact that there is a potential effect on residual bacteria in the anterior chamber after cataract surgery. Ferro, Feys and Mendivil and Mendivil (Ferro et al., 1997) (Feys et al., 1997) (Mendivil A. \& Mendivil M.P., 2000) failed to demonstrate a bactericidal effect following vancomycin in the bottle. In fact, the presence of S. epidermidis was the same in both the prophylaxis and the control arms.

Gordon (Gordon, 2001) believed that vancomycin should not be used as prophylaxis. Endophthalmitis has been reported despite its use, it is rapidly washed out from the anterior chamber in less than 4 hours and its concentration rapidly falls below MICs of gram-positive bacteria. Potentially, bacterial growth could be resumed once the antibiotic is washed-out of the anterior chamber. The authors agree with Gordon that there is no scientific evidence to use "in the bottle" vancomycin as a routine prophylaxis regimen and therefore do not recommend this measure.

Prophylactic antibiotic bolus injections into anterior chamber were described in the 1970's. In the early 1990's Gimbel (Gimbel et al., 1994) described a protocol to reduce endophthalmitis rates using intracameral vancomycin. After that, Montan (Montan et al., 2002) chose cefuroxime for endophthalmitis prophylaxis based on the ethiological spectrum of their previous endophthalmitis cases. They assumed that gram-negative bacteria would account for an insignificant amount of future cases. Thus, this regimen would effectively prevent infections due to gram-positive bacteria. They therefore concluded that cefuroxime was a valid alternative to vancomycin as a prophylactic agent even though enterococcal infections and some gram-negative bacteria were not covered. Vancomycin should be a lastresort antibiotic agent for treatment and not for prophylaxis, as recommended by the U.S. Centers for Disease Control and Prevention, Atlanta, Georgia. (Hospital Infection Control Practices Advisory Committee, 1995)

The European Society of Cataract and Refractive Surgeons (ESCRS) designed a multicentre prospective randomized partially masked study to investigate whether the incidence of endophthalmitis could be reduced using antibiotics (Barry et al., 2006) (ESCRS Endophthalmitis Study Group, 2007). Initially they were to recruit 35.000 patients having cataract surgery across several countries in Europe. Treatment effects were so marked that 16.603 patients were enough to halt the study and reach significant findings. One of the most interesting of them was that patients not receiving cefuroxime injection after the surgery were 4.92 times more likely to develop endophthtalmitis than patients receiving it. Intracameral injection of $1 \mathrm{mg}$ of cefuroxime in $0.1 \mathrm{ml}$ of saline had a statistically significant effect in reducing the risk of endophthalmitis after cataract phacoemulsification surgery. Previously, a Swedish report had advised of a 5-fold to 6-fold increased risk for endopththalmitis in patients not receiving intracameral cefuroxime (Montan et al., 2002). Two groups from Spain (Díez et al., 2009) (García-Sáenz et al., 2010) proved cefuroxime to be effective and safe in preventing endophthalmitis. Intracamerular cefuroxime proved to be more effective than subconjunctival cefuroxime in a paper published in 2008 (Yu-Wai-Man et al., 2008). Intracameral cefuroxime has a good safety profile and does not result in anterior segment toxicity (Montan et al., 2002) (Díez et al., 2009) (Gupta et al., 2005) (Yoeruek 
et al., 2008). Once in the anterior chamber, levels of cefuroxime over the MIC are maintained approximately 4 hours after the injection.

Despite the evidence supporting intracameral cephalosporins many surgeons in the United States prefer topical fourth-generation fluoroquinolones. They argue that intracameral cefuroxime must be prepared in a pharmacy department as it is not commercially available thus there is always a certain risk of errors in the dosage, $\mathrm{pH}$, stability or sterility of the drug. When prepared in a laminar flux cabin and stored in single patient doses these risks can be decreased significantly. Only a relatively small percentage of patients allergic to betalactams are allergic to cephalosporins too. Nevertheless, the authors recommend sending them to have allergy tests done before surgery is performed as the benefits of been able to use these on patients outweigh many-fold the risk of delaying elective surgery of the eye.

It has been suggested that moxifloxacin would be preferable to cefuroxime because of its broader spectrum of action, better MIC levels and lower bacterial resistance. (O'Brien et al., 2007) (Scoper, 2008) (Jensen et al., 2008). Moxifloxacin is available as a self-preserved commercial ophthalmic formulation and requires no special preparation for intracameral therapy. It has a $\mathrm{pH}$ of 6.8 and an osmolality of $290 \mathrm{mOsm} / \mathrm{kg}$ (compatible with human anterior chamber fluid) (Lane et al., 2008). It is diluted from the commercially available drops to a $1 \mathrm{mg} / 0.1 \mathrm{ml}$ solution as described by Arshinoff (Arshinoff, 2007). Intraocular toxicity was shown to be equivalent to standard vancomycin and saline control in a study in rabbit eyes by Kowalski (Kowalski et al., 2005). Retinal safety of intravitreal moxifloxacin up to $100 \mu \mathrm{g} / \mathrm{ml}$ in mice or $150 \mu \mathrm{g}$ in rabbits has been shown and caused no electroretinogram (ERG) or retinal histologic anormalities. Another study showed the safety of moxifloxacin in a concentration of $1 \mathrm{mg} / \mathrm{ml}$ and a dose of $100 \mu \mathrm{g} / 0.1 \mathrm{ml}$ evaluated by OCT and a retrospective review of clinical records (Arbisser, 2008). Lane observed that moxifloxacin in an intracameral dose of $250 \mu \mathrm{g} / 0.05 \mathrm{ml}$ was as safe as BSS in a 3 month follow up (Lane et al., 2008).

Once injected into the aqueous humour, high initial levels are achieved $(710 \mu \mathrm{g} / \mathrm{ml})$ and remained at $6 \mu \mathrm{g} / \mathrm{ml}$ or greater for 4 hours after the injection. This is well above the minimum bactericidal concentration against ocular isolates such as Staphylococcus aureus $(0.13 \mu \mathrm{g} / \mathrm{ml})$ or Staphylococcus epidermidis $(0.25 \mu \mathrm{g} / \mathrm{ml})$.

A recent cost-effectiveness analysis published in 2009 revealed that none of the fluoroquinolone antibiotics would have theoretical cost-effectiveness ratios superior to intracameral cefuroxime. Moreover, to achieve a threshold cost equivalence with intracameral cefuroxime, gatifloxacin or moxifloxacin should have an efficacy 9-fold to 30fold greater (Sharify et al., 2009).

Intracameral cefazoline been reported to be used in several papers mainly from Spain. Its choice as a prophylactic agent for postoperative endophthalmitis is based on the bacteria cultures and antibiograms from their own cases and data published (Garat et al., 2005) (Romero et al., 2006). These authors believe that the first-generation cephalosporin cefazoline $1 \mathrm{mg}$ in $0.1 \mathrm{ml}$ of saline injected in anterior chamber has a broader spectrum of activity against gram-positive bacteria than the second-generation cefuroxime. In fact, both cefuroxime and cefazolin have similar physicochemical and pharmacokinetic characteristics. Cefazolin is bactericidal against gram-positive cocci, specially Staphylococcus (except for methicilin-resistant Staphylococci) and Streptococcus. Garat et al (Garat et al., 2005) use 2.5 $\mathrm{mg} / 0.1 \mathrm{ml}$ bolus which has proved to be effective reducing endophthalmitis rates from $0.422 \%$ to $0.047 \%$ and to be safe. Unfortunately, cefazoline-resistant bacteria such as Enterococcus constitute an important gap in the coverage of gram-negative bacteria with 
this antibiotic. Endophthalmitis due to anaerobic bacteria is not prevented by cefazolin. These authors also suggest that cefazolin is easier to obtain and less expensive resulting in a very good option for developing countries. Cefazolin is used almost exclusively for surgical prophylaxis whereas cefuroxime is used systemically as a therapeutic option potently increasing pathogen resistance to the latter.

\subsubsection{Patching}

The use of an eye patch after cataract surgery is part of the postoperative routine in many hospitals. So-called "no stitch, no-patch" cataract surgery has become popular in the last few years because of modern surgical techniques. There is no clear evidence suggesting an influence of patching on the incidence of endophthalmitis. Patients tend to feel safer when the operated eye is patched, but it delays the beginning of postoperative antibiotic treatment. An alternative procedure may be patching the eye for a few hours and then initiating postoperative drop treatment.

\subsection{Postoperative prophylaxis}

\subsubsection{Postoperative antibiotics}

Although most ophthalmic surgeons apply an antibiotic ointment or solution at the end of the procedure, there is no literature to support the continued use of postoperative antibiotics. Several papers have been published on different ophthalmologists's practices worldwide after cataract surgery. Ninety six percent of the ophthalmologists in the United States (Masket, 1998) and ninety five percent in Australia (Morlet et al., 1998) answered positively when asked if they used postoperative antibiotics to prevent endophthalmitis.

If antibiotics are prescripted immediately after surgery the authors recommend that their use is prolonged until the incisions are sealed and to halt their instillation quickly to minimise the risk of development of resistant strains (Guías de Práctica Clínica de la Sociedad Española de Retina y Vítreo, 2011)

\section{Conclusions}

As previously discussed, some prophylactic measures have proved to be essential because there is scientific evidence to support them whilst others can be incorporated into clinical practice although their relevance is yet to be established.

To summarize, prior to surgery risk factors, especially those which are local, must be diagnosed in order to be adequately treated before the patient is booked for surgery. Preoperative antibiotics in the absence of risk factors have not been shown to reduce the incidence of endophthalmitis. When in the operating theatre proper draping is mandatory to ensure lid margin and eye lash isolation from de operating field. Disposable operating materials might reduce the risk of contamination and thus may be better than reusable material which should be monitored for adequate cleaning and sterilization. $10 \%$ povidoneiodine should be used to clean the skin and 5\% should be used in conjunctival fornices for 3 minutes (grouped evidence rating IIA, clinical recommendation B). In patients who are allergic to iodine, clorhexidine is a possible alternative. Care should be taken during corneal incision construction. The authors consider that corneal hydration and checking of wounds to assess if they are watertight are very useful measures and when there are any doubts concerning the wound's archithecture it should be sutured. There is not enough scientific evidence to recommend the use of subconjunctival or "in the bottle" antibiotics for the 
prophylaxis of endophthalmitis. In a clinical trial promoted by the ESCRS, intracameral cefuroxime $(1 \mathrm{mg}$ in $0.1 \mathrm{ml})$ in the bag and when the anterior chamber was not full, achieved a 5-fold decrease in the risk of postoperative endophthamitis (grouped evidence rating IB, clinical recommendation A). Its use also has a very good cost-effectiveness ratio. As of the present there are no double-masked, randomised clinical trials that recommend intracameral moxifloxacin at the end of phacoemulsification for postoperative endophthalmitis prophylaxis. Finally, there is no scientific evidence to support antibiotic use in the postoperative period to decrease the incidence of POE, but it seems reasonable to use them until the incisions are sealed- this normally means a week of topical antibiotics. Sharp suspension of the treatment and not tapering of these drops is recommended.

\section{References}

Andonegui J., Jiménez-Lasanta L., Alisadea D., \& Lameiro F. (2009). Brote de síndrome tóxico del segmento anterior después de cirugía vítrea. Arch Soc Esp Oftalmol, 2009, 84:403-406. ISSN: 0365-6691

Arbisser L.B. (2008). Safety of intracameral moxifloxacin for prophylaxis of endophthalmitis after cataract surgery. J Cataract Refract Surg 2008, 34: 1114-1120. ISSN: 0886-3350

Arciola C.R., Caramazza R., \& Pizzoferrato A. (1994). In vitro adhesion of Staphylococcus epidermidis on heparin-surface modified intraocular lenses. J Cataract Refract Surg, 1994, 20: 158-161. ISSN: 0886-3350

Arshinoff S.A. (2007). "Advantages and Use of Intracameral Moxifloxacin for Bacterial Prophylaxis in Cataratact Surgery", poster presented at the ASCRS Symposium on Cataract, IOL and Refractive Surgery, San Diego, California, USA, April 2007

Avisar R., \& Weinberger D. (2010). Corneal endotelial morphologic features in toxic anterior segment syndrome. Cornea, 2010, 29: 251-153. ISSN: 0277-3740

Baillif S., Ecochard R., Hartmann D., Freney J., \& Kodjikian L. (2009). Intraocular lens and cataract surgery: comparison between bacterial adhesion and risk of postoperative endophthalmitis according to intraocular lens biomaterial. J Fr Ophtalmol, 2009, 32: 515-28. ISSN: 0181-5512

Ball J.L, Barrett G.D. (2006). Prospective randomized controlled trial of the effect of intracameral vancomycin and gentamicin on macular retinal thickness and visual function following cataract surgery. J Cataract Refract Surg, 2006, 32:789-794. ISSN: 0886-3350.

Barry P., Seal D.V., Gettinby G., Lees F., Peterson M., \& Revie C.W. (2006). ESCRS study of prophylaxis of postoperativeendophtalmitis after cataract surgery: Preliminary report of principal results from a European multicenter study. J Cataract Refract Surg, 2006, 32: 407-410. ISSN 0886-3350

Breebaart A.C., Nuyts R.M.M.A., Pels E., Edelhauser H.F., \& Verbraak F.D. (1990). Toxic endotelial cell destruction of the cornea after extracapsular cataract surgery. Arch Ophthalmol, 1990, 108: 1121-1125. ISSN:0003-9950

Buzard K., Zhang J.R., Thumann G., Stripecke R., \& Sunalp M. (2010). Two cases of toxic anterior segment syndrome from generic trypan blue. J Cataract Refract Surg, 2010, 36(12): 2195-2199: ISSN 0886-3350

Cakir M., Imamoğlu S., Cekiç O., Bozkurt E., Alagöz N., Oksüz L., \& Yilmaz O.F. (2009). An outbreak of early-onset endophthalmitis caused by Fusarium species following cataract surgery. Curr Eye Res, 2009, 34(11):988-995. ISSN 0271-3683 
CDC. Recommendations for preventing the spread of vancomycin resistance.(1995). Morb Mort Wkly Rep, 1995,44(RR-12):1-13. ISSN: 0886-3350

Ciulla T.A., Starr M.B., \& Masket S. (2002). Bacterial endophthalmitis prophylaxis for cataract surgery: an evidence-based update. Ophthalmology, 2002, 109: 13-24. ISSN: 0161-6420

Cusumano A., Busin M., \& Spitznas M. (1994). Bacterial growth is significantly enhanced on foldable intraocular lenses. Arch Ophthalmol, 1994, 112: 1.015-1.016. ISSN: 0003-9950

Díez M.R., de la Rosa G., Pascual R., Girón C., \& Arteta M. (2009). Prophylaxis of the postoperative endophthalmitis with cefuroxime intracameral: a five years'experience. Arch Soc Esp Oftalmol,. 2009, Feb, 84(2):85-89. ISSN: 0365-6691

Driebe W.T., Mandelbaum S., Forster R.K., Schwartz L.K., \& Culbertson W.W. (2006). Pseudophakic endophthalmitis. Diagnosis and management Ophthalmology, 1986, 93:442-8. ISSN: 0161-6420

Duffy R.E., Brown S.E., Caldwell K.L., Lubniewski A., Anderson N., Edelhauser H., Holley G., Tess A., Divan H., Helmy M., Arduino M., \& Jarvis W.R. (2000). An epidemic of corneal destruction caused by plasma gas sterilization; the Toxic Endothelial Cell Destruction syndrome investigate Team. Arch Ophthalmol, 2000, 118:1167-1176. ISSN: 0003-9950

Eleftheriadis H., Cheong M., Sanderman S., Syam P.P., Brittain P., Klintworth G.K., Lloyd A., \& Liu C. (2002). Corneal toxicity secondary to inadvertent use of benzalkonium chloride preserved viscoelastic material in cataract surgery. Br J Opthalmol, 2002, 86: 299-305. ISSN 1468-2079

Eloy R., Parrat D., \& Duc T.M. (1993). In vitro evaluation of inflammatory cell response after CF4 plasma surface modification of polymethyl methacrylate intraocular lenses. $J$ Cataract Refract Surg, 1993, 19: 364-370. ISSN: 0886-3350

Endophthalmitis Vitrectomy Study Group. (1995). Results of the Endophthalmitis Vitrectomy Study: a randomized trial of immediate vitrectomy and of intravenous antibiotics for the treatment of postoperative bacterial endophthalmitis. Arch Ophthalmol, 1995, 113(12):1479-1496. ISSN: 0003-9950

Endophthalmititis Vitrectomy Study Group. (1995). Results of the Endophthalmitis Vitrectomy Study. A randomized trial of immediate vitrectomy and of intravenous antibiotics for the treatment of postoperative bacterial endophthalmitis. Arch Ophthalmol, 1995, 113: 1479-1496. ISSN: 0003-9950

ESCRS Endophthalmitis Study Group. (2007). Prophylaxis of postoperative endophthalmitis following cataract surgery: results of the ESCRS multicenter study and identification of risk factors. J Cataract Refract Surg, 2007, 33: 978-988. ISSN: 08863350

Fernández-Rubio E., Cuesta-Rodriguez T., \& Cortés-Valdés C. (2004). Antibioterapia tópica preoperatoria en la cirugía de cataratas. Arch Soc Esp Oftalmol, 2004, 79: 213-220. ISSN: 0365-6691

Ferro J.F., De-Pablos M., \& Logrono M.J. (1997). Postoperative contamination alter vancomycin and gentamycin during phacoemulsification. Arch Ophthalmol, 1997,115:165-170. ISSN: 0003-9950

Feys J.F., Salvanet-Bouccara A., Emond J., \& Dublanchet A. (1997). Vancomycin prophylaxis and intraocular contamination during cataract surgery. J Cataract Refract Surg, 1997, 23:894-897. ISSN: 0886-3350 
Fine I.H., Hoffman R.S., \& Oacker M. (2007). Profile of clear corneal cataract incisions demonstrated by ocular coherence tomography. J Cataract Refract Surg, 2007, 33(1):94-97. ISSN: 0886-3350

Garat M., Moser C.L., Alonso-Tarrés C., Martín-Baranera M., \& Alberdi A. (2005). Intracameral cefazolin to prevent endophthalmitis in cataract surgery:3-year retrospective study. J Cataract Refract Surg, 2005, 31(11):2230-4. ISSN: 0886-3350

Garcia-Arumi J., Fonollosa A., Sarasols L., Fina F., Martinez-Castillo V., Boixader A., Zapata M.A., \& Campins M. (2007). Topical anestesia: posible risk factor for endophthalmitis alter cataract extraction. J Cataract Refract Surg, 2007, 33:989-992. ISSN: 0886-3350

García-Sáenz M.C., Arias-Puente A., Rodríguez-Caravaca G., \& Bañuelos J.B. (2010). Effectiveness of intracameral cefuroxime in preventing endophthalmitis after cataract surgery. J Cataract Refract Surg, 2010, 36:203-207. ISSN: 0886-3350

Gills J.P (1991). Filters and antibiotics in irrigating solution for cataract surgery [letter]. J Cataract Refract Surg, 1991, 17:385. ISSN: 0886-3350.

Gimbel H.V., Sun R., \& DeBroff B.M. (1994). Prophylactic intracameral antibiotics during cataract surgery:the incidence of endophthalmitis and corneal endothelial loss. Eur J Implant refract Surg, 1994, 6:280-285

Gordon Y.J. (2001). Vancomycin prophylaxis and emerging resistance: Are Ophthalmologists the villains? The heroes? Am J Ophthalmol, 2001, 131(3):371-376. ISSN: 0002-9394

Greenbaum S. (2007). Topical anesthesia and postoperative endophthalmitis. J Cataract Refract Surg, 2007, 33:2011-2012. ISSN: 0886-3350

Groden L.R., Murphy B., Rodnite J., \& Genvert G.I. (1991). Lid flora in blepharitis. Cornea, 1991, 10:1:50-53. ISSN: 0277-3740

Gupta M.S., McKee H.D., Saldana M., \& Stewart O.G. (2005). Macular thickness after cataract surgery with intracameral cefuroxime. I Cataract Refract Surg, 2005, 31:1163-1166. ISSN: 0886-3350

Guzel A.G., Ozekinci T., Ozkan U., Celik Y., Ceviz A., \& Belen D. (2009). Evaluation of the skin flora alter clorhexidine and povidone-iodine preparation in neurosurgical practice. Surgical Neurology, 2009, 71:207-210. ISSN: 0090-3019

Hellinger W.C., Hasan S.A., Bacalis L.P., Thornblom DM,Beckmann S.C., Blackmore C., Forster T.S., Tirey J.F., Ross M.J., Nilson C.D., Mamalis N., Crook J.E., Bendel R.E., Shetty R., Stewart M.W., Bolling J.P., \& Edelhauser H.F. (2006). Outbreak of toxic anterior segment syndrome following cataract surgery associated with impurities in autoclave steam moisture. Infect Control Hosp Epidemio,l 2006, 27: 294-298. ISSN: 0899-823X

Hellinger W. C., Bacalis L. P., Edenhauser H. F.,Mamalis M., Milstein B., Masket S. (2007). Recommended practices for cleaning and sterilizing intraocular surgical instruments. J Cataract Refract Surg, 2007, 33:1095-1100. ISSN: 0886-3350

Heuermann T., Hartman C., \& Anders N. (2002). Long-term endotelial cell loss after phacoemulsification; peribulbar anesthesia versus intracameral lidocaine $1 \%$; prospective, randomized clinical trial. J Cataract Refract Surg, 2002, 28:639-643. ISSN: 0886-3350.

Holland S.P., Lee T.L., \& Morck D.W. (2007). Update on toxic anterior segment syndrome. Curr Opin Ophthalmol, 2007, 18:4-8. ISSN: 1040-8738 
Hollander D.A., Vagefi M.R., Seiff S.R., \& Stewart J.M. (2006). Bacterial endophthalmitis after resident-performed cataract surgery. Am J Ophthalmol, 2006,141 (5):949-51. ISSN: 0002-9394

Hospital Infection Control Practices Advisory Committee (HICPAC). (1995). Recommendations for preventing the spread of vancomycin resistance. Infect Control Hosp Epidemiol, 1995, 16:105-113, erratum, 498. ISSN: 0899-823X

Jensen M.K., Fiscella R.G., Moshirfar M., \& Mooney B. (2008). Third- and fourth-generation fluoroquinolones: retrospective comparison of endophthalmitis after cataract surgery performed over 10 years. J Cataract Refract Surg, 2008, 34:1460-1467. ISSN: 0886-3350

Jun E.J., \& Chung S.K. (2010). Toxic anterior segment syndrome after cataract surgery, J Cataract Refract Surg, 2010, 36: 344-346. ISSN: 0886-3350.

Kadonoso K., Ito N., Yazama F., Nishide T., Sugita M., Sawada H., \& Ohno S. (1998). Effect of intracameral anesthesia on the corneal endotelio. J Cataract Refract Surg, 1998, 24:1377-1381. ISSN: 0886-3350.

Kamalarajah S. Ling R., Silvestri G., Sharma N.K., Cole M.D., Cran G., \& Best RM. (2007). Presumed infectious endophthalmitis following cataract surgery in the UK: a casecontrol study of risk factors. Eye, 2007, 21(5):577-9. ISSN: 0950-222X

Kelkar A., Kelkar J., Amuaku W., Kelkar U., \& Shaikh A. (2008). How to prevent endophthalmitis in cataract surgeries? Indian J Ophthalmol, 2008, 56(5):403-7. ISSN: 0301-4738

Khan R.I., Kennedy S., \& Barry P. (2005). Incidence of presumed postoperative endophthalmitis in Dublin for a 5-year-period (1997-2001). J Cataract Refract Surg, 2005, 31: 1575-1581. ISSN 0886-3350

Kim J.Y., Ali R., Cremers S.L., \& Henderson B.A. (2007). Perioperative prophylaxis for postcataract extraction endophthalmitis. Int Ophthalmol Clin, 2007, 47(2):1-14. ISSN: 0020-8167

Kowalski R.P., Kowalski B.R., Romanowski E.G., Mah F.S., Thompson P.P., \& Gordon Y.J. (2006). The in vitro impact of moxifloxacin and gatifloxacin concentration $(0.5 \%$ vs $0.3 \%)$ and the addition of benzalkonium chloride on antibacterial efficacy. Am J Ophthalmol, 2006, 142:730-735. ISSN 0002-9394

Kowalski R.P., Romanowski E.G., Mah F.S., Yates K.A., \& Gordon Y.J. (2005). Intracameral vigamox (moxofloxacin 0.5\%) is non-toxic and effective in preventing endophthalmitis in a rabbit model. Am J Ophthalmol, 2005, 497e1-497e8. ISSN 00029394

Kramann C., Pitz S., Schewenn O., Haber M., Hommel G., \& Pfeiffer N. (2001). Effects of intraocular cefotaxime on the human corneal endothelium. J Cataract Refract Surg, 2001, 27:250-255. ISSN: 0886-3350

Kreisler K.R., Martin S.S., Young C.W., Anderson C.W., \& Mamalis N. (1992). Postoperative inflammation following cataract extraction caused by bacterial contamination of the cleaning bath detergent. J Cataract Refract Surg, 1992, 18:106-110. ISSN: 0886-3350.

Kutty P.K, Forster T.S., Wood-Koob C., Thayer N., Nelson R.B., Berke S.J., Pontacolone L., Beardsley T.L., Edelhauser H.F., Arduino M.J., Mamalis N., \& Sriinivasan A. (2008). Multistate outbreak of toxic anterior segment síndrome, 2005. J Cataract Refracr Surg, 2008, 34:585-590. ISSN: 0886-3350 
Lacey R.W. \& Catto A. (1993). Action of povidone-iodine against methicillin-sensitive and resistant cultures of Staphylococcus aureus. Postgrad Med J, 1993, 69: S78-S83.

Lane S.S., Osher R.H., Masket S., \& Belani S. (2008). Evaluation of the safety of prophylactic intracameral moxifloxacin in cataract surgery. J Cataract Refract Surg, 2008, 34:14511459. ISSN: 0886-3350

Liesegang T.J.(2001). Use of antimicrobials to prevent postoperative infection in patients with cataracts. Current Opinion in Ophthalmology, 2001, 12:68-74. ISSN 1040-8738

Liu H., Routley I., \& Teichmann K.D. (2001). Toxic endotelial cell destruction from intraocular benzalkonium chloride. J Cataract Refract Surg, 2001, 27: 1746-1750. ISSN: 0886-3350

Mammalis N., Edelhauser H.F., Dawson D.G., Chew J., LeBoyer R.M., \& Werner L. (2006). Toxic anterior segment síndrome. J Cataract Refract Surg, 2006, 32:324-333. ISSN: 0886-3350

Masket S. (1998). Preventing, diagnosing, and treating endophthalmitis. J Cataract Refract Surg, 1998, 24:725-726. ISSN: 0886-3350

Masket S. (2007). Reply: Patching to prevent postoperative endophthalmitis. J Cataract Refract Surg, 2007, 33 (10):1673. IOSSN: 0886-3350

Mathys K.C., Cohen K.L., \& Bagnell C.R (2008). Ideentification of unknown intraocular material after cataract surgery: evaluation of a potential cause of toxic anterior segment syndrome. J Cataract Refract Surg, 2008, 34:465-469. ISSN: 0886-3350

Melo G.B., Bispo P.J., Regatieri C.V., Yu M.C., Pignatari A.C., \& Höfling-Lima A.L.. (2010). Incidence of Endophthalmitis after cataract surgery (2002-2008) at a Brazilian university-hospital. Arq Bras Oftalmol, 2010, 73(6): 505-507. ISSN: 0004-2749

Mendivil A. \& Mendivil M.P. (2000). The effect of topical povidone-iodine, intraocular vanomycin or both in aqueous humorcultures at the time of cataract surgery. Am J Ophthalmol 2000, 131: 293-300. ISSN: 0002-9394

Menikoff J.A., Speaker M.G., Marmor M., \& Raskin E.M. (1991). A case-control study of risk factors for postoperative endophthalmitis. Ophthalmology, 1991, 98:1761-1768. ISSN: 0161-6420

Miller J., Scott I.U., Flynn H.W., Smiddy W.E., Newton J., \& Miller D. (2005). Acute-onset Endophthalmitis after cataract surgery 2000-2004: Incidence, clinical settings and visual acuity outcomes after treatment. Am J Ophthalmol, 2005, 139(6):983-987. ISSN: 0002-9394

Mills D.M., Bodman M.G., Meyer D.R., \& Morton A.D. (2007). 3rd; ASOPRS Dacryocystitis Study Group. The microbiologic spectrum of dacryocystitis: a national study of acute versus chronic infection. Ophthal Plast Reconstr Surg, 2007, 23: 302-306. ISSN: 1537-2677

Miño de Kaspar H., Chang R.T., Singh K., Egbert P.R., Blumenkranz M.S., \& Ta CN. (2005). Prospective randomized comparison of 2 different methods of $5 \%$ povidone-iodine applications for the anterior segment intraocular surgery. Arch Ophthalmol, 2005, 123:161-165. ISSN: 0003-9950

Miño de Kaspar H., Shriver E.M., Nguyen E.V., Egbert P.R., Singh K., Blumenkranz M.S., \& Ta C.N.(2003). Risk factors for antibiotic-resistant conjunctival bacterial flora in patients undergoing intraocular surgery. Graefes Arch Clin Exp Ophthalmol, 2003, 241(9):730-733. Epub 2003 Aug 20. ISSN: 0721-832X 
Miño De Kaspar H., Ta C.N., Froehlich S.J., Schaller U.C., Engelbert M., Klauss V., \& Kampik A. (2009). Prospective study of risk factors for conjunctival bacterial contamination in patients undergoing intraocular surgery. Eur J Ophthalmol, 2009,19(5):717-722. ISSN 1120-6721

Monson M.C., Mamalis N., \& Olson R.J. (1992). Toxic anterior segment inflammation following cataract surgery. J Cataract Refract Surg, 18, 1992,184-189,ISSN: 0886-3350

Montan P., Montan P., Wejde G., Setterquist, Koranyi G., \& Rylander M. (2002). Prophylactic intracameral cefuroxime. Evaluation of safety and kinetics in cataract surgery. J Cataract Refract Surg, 2002, 28:982-987. ISSN: 0886-3350

Montan P., Wejde G., Koranyi G., \& Rylander M. (2002). Prophylactic intracameral cefuroxime. Efficacy in preventing endophthalmitis after cataract surgery. J Cataract Refract Surg, 2002, 28:977-981. ISSN: 0886-3350

Morlet N., Gatus B., \& Coroneo M. (1998). Patterns of peri-operative prophylaxis for cataract surgery: a survey of Australian ophthalmologists. Aust NZ J Ophthalmol, 1998, 26:5-12. ISSN: 0814-9763

Nakata K., Inoue Y., Harada J., Maeda N., Watanabe H., Tano Y., Shimomura Y., Harino S., \& Sawa M. (2000). A high incidence of Staphylococcus aureus colonization in the external eyes of patients with atopic dermatitis. Ophthalmology, 2000, 107: 2167-2171. ISSN: 0161-6420

$\mathrm{Ng}$ E. \& Barrett G.D., Baudman R. (1996). In vitro bacterial adherence to hydrogel and PMMA intraocular lenses. J Cataract Refract Surg, 1996, 22 (sup 2): 1.331-1.335. ISSN: 0886-3350

O'Brien T.P., Arshinoff S.A., \& Mah F.S. (2007). Perspectives on antibiotics for postoperative endophthalmitis prophylaxis: potential role of moxifloxacin. J Cataract Refract Surg, 2007, 33:1790-1800. ISSN: 0886-3350

Parikh C, Sippy B.D., Martin D.F., Edelhauser H.F. (2002). Effects of enzymatic sterilization detergents on the corneal endothelium. Arch Ophthalmol, 2002, 120: 165-172. ISSN: 0003-9950

Parikh C.H., \& Edelhauser H.F. (2003). Ocular surgical pharmacology: corneal endotelial safety and toxicity. Curr Opin Ophthalmol, 2003, 14: 178-185. ISSN: 1040-8738

Peck C.M.C., Brubaker J., Clouser S., Danford C., Edelhauser HF., \& Mamalis N. (2010). Toxic anterior segment syndrome: common causes. J Cataract Refract Surg, 2010, 36: 1073-1080. ISSN: 0886-3350

Pijla B.J., Theelena T., Tilanusa M.A., Rentennaarb R., \& Cramaa N. (2010). Acute endophthalmitis after cataract surgery: 250 consecutive cases treated at a tertiary referral center in the Netherlands. Am J Ophthalmol, 2010, 149:482-287.e2. ISSN: 0002-9394

Pinna A., Usai D., Sechi L.A., Zanetti S., Jesudasan N.C., Thomas P.A., \& Kaliamurthy J. (2009). An outbreak of post-cataract surgery endophthalmitis caused by Pseudomonas aeruginosa. Ophthalmology, 2009, 116(12):2321-2326.e1-4. Epub 2009 Oct 7. ISSN: 01616-6420

Romero P., Méndez I., Salvat M., Fernández J., \& Almena M. (2006). Intracameral cefazolin as prophylaxis against endophthalmitis in cataract surgery. J Cataract Refract Surg, 2006, 32:438-441. ISSN: 0886-3350 
Sato T., Emi K., Ikeda T., Bando H., Sato S., Morita S., Oyagi T., \& Sawada K. (2010). Severe intraocular inflammation after intravitreal injection of bevacizumab. Ophthalmology, 2010, 117(3):512-6, 516.e1-2. Epub 2010 Jan 19. ISSN 0161-6420

Schauersberger J., Amon M., Aichinger D., \& Georgopoulos A. (2003). Bacterial adhesion to rigid and foldable posterior chamber intraocular lenses: in vitro study. J Cataract Refract Surg, 2003, 29:361-6. ISSN: 0886-3350

Scoper S.V. (2008). Review of third- and fourth-generation fluoroquinolones in ophthalmology: in-vitro and in-vivo efficacy. Adv Ther, 2008, 25:979-994

SERV. "Endoftalmitis infecciosa. Guías de Práctica clínica de la SERV". (2011). Available in www.serv.es

Sharify E., Porco T.C., \& Naseri A. (2009). Cost-effectiveness analysis of intracameral cefuroxime use for prophylaxis of endophtalmitis after cataract surgery. Ophthalmology, 2009, 16:1887-1896. ISSN: 0161-6420

Shaw J., Smith E.F., Deai R.U., Enriquez B., \& Schrier A. (2010). Can intraocular lenses deliver antibiotics intracamerally? J Ocul Pharmacol Ther, 2010, 26 (6): 587-589. ISSN: 1080-7683

Speaker M.G., Milch F.A., Shah M.K., Eisner W., \& Kreiswirth B.N. (1991). Role of external bacterial flora in the pathogenesis of acute postoperative endophthalmitis. Ophthalmology, 1991, 98: 639-649. ISSN: 0161-6420

Vasavada A.R., Gajjar D., Raj S.M., Vasavada V., \& Vasavada V. (2008). Comparison of 2 moxifloxacin regimens for preoperative prophylaxis: prospective randomized triple-masked trial. Part 2: Residual conjunctival flora. J Cataract Refrac Surg, 2008, 34:1383-1388. ISSN 0886-3350.

Wallace E.J., Imrie F., Roxburgh S., Coleiro J., \& Ironside J. (2007). Epithelial downgrowth as a complication of toxic anterior segment syndrome. J Cataract Refract Surg, 33, 2007, 1976-1977. ISSN: 0886-3350

Werner L., Sher J.H., Taylor J.R., Mamalis N., Nash W.A., Csordas J.E., Green G., Maziarz E.P., \& Liu X.M. (2006). Toxic anterior segment syndrome and possible association with ointment in the anterior chamber following cataract surgery. J Cataract Refract Surg, 2006, 32:227-235. ISSN: 0886-3350

Yoeruek E., Spitzer M.S., Saygili O., Tatar O., Biedermann T., Yoeruek E., Bartz-Schmidt K.U., \& Szurman P. (2008). Comparison of in vitro safety profiles of vancomycin and cefuroxime on human corneal endothelial cells for intracameral use. J Cataract Refract Surg, 2008, 34:2139-2145. ISSN: 0886-3350

Yu-Wai-Man P., Morgan S.J., Hildreth A.J., Steel D.H., \& Allen D. (2008). Efficacy of intracameral and subconjunctival cefuroxime in preventing endophthalmitis after cataract surgery. J Cataract Refract Surg, 2008, 34:447-451. ISSN: 0886-3350 